\title{
ANALISIS KINERJA KEUANGAN PT. PEGADAIAN CABANG ULAK KARANG
}

\author{
Ivo Zainal arifin, Doni Marlius \\ Akademi Keuangan dan Perbankan Padang \\ donimarlius@akbpstie.ac.id
}

\begin{abstract}
The purpose of this study is to determine the condition of the financial performance of PT. Pegadaian based on liquidity, solvency and profitability ratios for 2014-2016. Field Research That is a research method by going directly to the company which is the object of study to examine the results of the data that are the object of study. Data collection techniques are carried out by interviewing and observing. Library Studies Namely research that conducts into the library several scientific books and writings relating to the discussions conducted. The total assets in 2014 were Rp. 14,657,224,764 and increa sed in 2015 to Rp. 15,475,878,645. Total assets in 2016 were Rp. 16,676,381,297. In 2014 with total sales of Rp.21,388,740 companies obtained a profit of Rp.2,648,492,739. In 2015 sales were stable, where the total sales amounted to Rp.2,648,492,739 and earned an increase in profit from the previous year, where profits obtained from 2016 were Rp. $3,434,318,246$.
\end{abstract}

Keywords: Financial Performance

\section{PENDAHULUAN}

Perkembangan posisi keuangan mempunyai arti yang sangat penting bagi perusahaan. Untuk melihat sehat tidaknya suatu perusahaan tidak hanya dapat dinilai dari keadaan fisiknya saja, misalnya dilihat dari gedung, pembangunan atau ekspansi. Laporan keuangan pada perusahaan dapat menunjukan kinerja yang telah dicapai pada suatu waktu serta untuk mengetahui kemampuan perusahaan dalam mengatasi masalah-masalah keuangan perusahaan serta mengambil keputusan yang cepat dan tepat. Menurut Muslich (2003) menyatakan bahwa analisis rasio keuangan merupakan alat utama dalam analisis keuangan, karena analisis ini dapat digunakan untuk menjawab berbagai pertanyaan tentang keadaan perusahaan. PT. Pegadaian (Persero) yang sebelumnya berbentuk badan usaha PERUM ini merupakan salah satu dari Badan Usaha Milik Negara. PT. Pegadaian (Persero) adalah lembaga formal di Indonesia yang berdasarkan hukum yang diperbolehkan melakukan pembiayaan dengan bentuk penyaluran kredit atas dasar hukum gadai. Data mengenai keuangan PT. Pegadaian Ulak Karang dalam kurun waktu 2014 s/d 2016, dapat di lihat pada tabel berikut 
Tabel

Laporan Laba Rugi PT. Pegadaian Ulak Karang

Tahun 2014-2016

\begin{tabular}{|l|c|c|c|}
\hline Keterangan & $\mathbf{2 0 1 4}$ & $\mathbf{2 0 1 5}$ & $\mathbf{2 0 1 6}$ \\
\hline Penjualan & 2.636 .198 .071 & 3.408 .166 .010 & 3.436 .365 .544 \\
\hline Laba Bersih & -1.087 .888 .002 & -751.419 .641 & 220.424 .385 \\
\hline
\end{tabular}

Sumber data: Laporan Laba Rugi PT. Pegadaian Ulak Karang

Pada Tahun 2014 dengan jumlah penjualan sebesar Rp.2.636.198.071 perusahaan memperoleh laba sebesar Rp.-1.087.888.002 Pada tahun 2015 penjualan stabil, dimana jumlah penjualan sebesar Rp.3.408.166.010 dan memperoleh laba yang neningkat dari tahun sebelumnya sebesar Rp. -751.419.641. Pada tahun 2016 penjualan mengalami kenaikan yang jauh pesat peningkatannya, dimana penjulan tahun 2016 adalah sebesar Rp. 3.436.365.544 laba yang diperoleh oleh perusahan mengalami sedikit peningkatan dari tahun sebelumnya dimana laba yang diperoleh dari tahun 2016 adalah sebesar Rp.220.424.385.

\section{Rumusan Masalah}

Berdasarkan latar belakang masalah diatas maka rumusan masalah dalam penelitian ini adalah:

a. Bagaimana kinerja keuangan PT. Pegadaian berdasarkan rasio likuiditas pada tahun 2014-2016. b. Bagaimana kinerja keuangan PT. Pegadaian berdasarkan rasio solvabilitas pada tahun 2014-2016.

c. Bagaimana kinerja keuangan PT. Pegadaian berdasarkan rasio profitabilitas pada tahun 2014-2016.

\section{Tinjauan Pustaka}

\section{Pegadaian}

Menurut Undang-undang Hukum Perdata (KUHP) Pasal 1150 disebutkan bahwa gadai adalah suatu hak yang diperoleh seorang yang berpiutang atas suatu barang bergerak, yang diserahkan kepadanya oleh seorang yang memiliki utang atau oleh seorang lain atas namanya, dan yang memberikan kekuasaan kepada orang yang berpiutang itu untuk mengambil pelunasan dari barang tersebut diprioritaskan daripada orang yang berpiutang lainnya, dengan pengecualian biaya untuk melelang barang tersebut dan biaya yang telah dikeluarkan untuk menyelamatkan setelah barang itu digadaikan. 
Tabel

Perbedaan Pegadaian Konvensional dengan Pegadaian Syariah

\begin{tabular}{|l|l|}
\hline Pegadaian Konvensional & Pegadaian Syariah \\
\hline $\begin{array}{l}\text { Didasarkan pada Peraturan Pemerintah } \\
\text { Nomor 103 tahun 2000 }\end{array}$ & $\begin{array}{l}\text { Didasarkan pada Peraturan Pemerintah } \\
\text { Nomor 103 tahun 2000 dan Hukum Agama } \\
\text { Islam }\end{array}$ \\
\hline $\begin{array}{l}\text { Biaya administrasi berdasarkan } \\
\text { prosentase berdasarkan golongan } \\
\text { barang }\end{array}$ & $\begin{array}{l}\text { Biaya administrasi menurut ketetapan } \\
\text { berdasarkan golongan barang }\end{array}$ \\
\hline
\end{tabular}

Sumber: Perbedaan pegadaian konvensional dan syariah Caskey (1991)

Landasan hukum kegiatan pegadaian atau usaha gadai yaitu Peraturan Pemerintah (PP) Nomor 10 Tahun 1990 tentang Perusahaan Umum Pegadaian. Dalam PP tersebut, pegadaian atau usaha gadai dimaknai sebagai kegiatan menjaminkan barang-barang berharga kepada pihak tertentu, guna mendapatkan sejumlah uang senilai barang yang dijaminkan yang akan ditebus sesuai dengan kesepakatan antara nasabah dengan lembaga gadai

\section{Kinerja Keuangan}

Kinerja perusahaan merupakan suatu gambaran tentang kondisi keuangan suatu perusahaan yang dianalisis dengan alat-alat analisis keuangan, sehingga dapat diketahui mengenai baik buruknya keadaan keuangan suatu perusahaan yang mencerminkan prestasi kerja dalam periode tertentu. Hal ini sangat penting agar sumber daya digunakan secara optimal dalam menghadapi perubahan lingkungan.

Analisis Kinerja Keuangan PT.
Pegadaian Dengan Menggunakan
Rasio-Rasio Keuangan
Dengan menggunakan analisis terhadap laporan keuangan akan tergambar suatu ringkasan laporan neraca saldo selama periode yang diteliti. Langkah-langkah yang perlu dilakukan terhadap analisis ini adalah me perbandingan antara beberapa periode yang bersangkutan dan melakukan analisis dengan menggunakan rasio keuangan

Berikut penyajian laporan keuangan PT. Pegadaian untuk tiga periode dari tahun 2014 sampai dengan tahun 2016.

\section{Neraca}

Penyusuan neraca yang dilakukan oleh PT. Pegadaian Ulak Karang adalah bentuk $\mathrm{T}$, dimana dalam bentuk ini semua aktiva nampak jelas dibagian kiri yang selanjutnya diikuti oleh passiva sebelah kanan yang terdiri dari hutang dan modal. Neraca Pegadaian Ulak Karang disusun dan disajikan untuk dapat menmberikan informasi mengenai posisi dan kond isi keuangan untuk setiap periode yang bersangkutan bagi pihak-pihak yang berkepentingan terhadap perusahaan. Berikut ini adalah posisi keuangan PT. Pegadaian Ulak Karang untuk periode 2014 samapi dengan periode 2016. 
Tabel Posisi Keuangan PT. Pegadaian Ulak Karang

Tahun 2014-2016

\begin{tabular}{|l|c|c|c|}
\hline Keterangan & $\mathbf{2 0 1 4}$ & $\mathbf{2 0 1 5}$ & $\mathbf{2 0 1 6}$ \\
\hline Aktiva Lancar & 13.342 .211 .641 & 14.071 .755 .266 & 15.990 .493 .516 \\
\hline Aktiva Tetap & 958.444 .307 & 922.080 .727 & 1.561 .106 .867 \\
\hline Total Aktiva & 14.657 .224 .764 & 15.475 .878 .645 & 16.676 .381 .297 \\
\hline $\begin{array}{l}\text { Total kewajiban dan } \\
\text { modal }\end{array}$ & 560.551 .013 & 281.421 .320 & 486.525 .186 \\
\hline
\end{tabular}

Sumber data: laporan Posisi Keuanagan PT. Pegadaian Ulak Karang

Pada tahun 2014 jumlah aktiva lancar yang dimiliki oleh perusahaan sebesar Rp.13.342.211.41 sedangkan jumlah aktiva tetap yang dimiliki perusahaan adalah sebesar Rp. 958.444.307. Pada tahun 2015 jumlah aktiva lancar yang dimiliki perusahaan adalah Rp.14.071.755.266 dimana mengalami peningkatan sebelumnya sebesar Rp.29.543.625. Aktiva tetap yang dimilki perusahaan sebesar Rp.922.080.727 mengalami penurunan sebesar Rp.36.363.580. Total keseluruhan aktiva pada tahun 2014 adalah Rp.14.657.224.764 dan mengalami peningkatan pada tahun 2015 menjadi Rp.15.475.878.645.

Jumlah aktiva lancar yng dimiliki perusahaan pada tahun 2016 adalah sebesar Rp.15.990.493.516, menaik dari tahun sebelumnya sebesar Rp.1.918.738.250, aktiva tetep yang dimiliki perusahaan pada tahun 2016 mengalami peningkatan dari tahun sebelumnya sebesar Rp.639.026.140 dimana aktiva tetap tahun 2016 adalah sebesar Rp.1.561.106.867. Total aktiva pada tahun 2016 adalah sebesar Rp.16.676.381.297 mengalami peingkatan dari tahun sebelumnya sebesar Rp.1.200.502.652.

Jumlah kewajiban PT. Pegadaian Ulak Karang Pada Tahun 2014 adalah Sebesar Rp.560.551.013 sedangkan pada tahun 2015 adalah sebesar Rp.281.421.320 mengalami penurunan sebesar Rp.279.129.693. Pada tahun 2016 total kewajiban mengalami peningkatan sebesar Rp.205.103.866, dimana kewajiban pada tahun 2016 sebesar Rp.486.525.186.

\section{Analisis Kinerja Keuangan Dengan} Rasio-Rasio Keuangan

1. Rasio Likuiditas

Fred Weston dikutip dari Kasmir (2008:129): menyebutkan bahwa rasio likuiditas (liquidity ratio) merupakan rasio yang menggambarkan kemampuan perusahaan dalam memenuhi kewajiban (utang) jangka pendek.

\section{a. Rasio Lancar (Current Ratio)}

Rasio lancar merupakan rasio untuk mengukur kemampuan perusahaan dalam membayar kewajiban jangka pendek atau utang yang segera jatuh tempo dengan aktiva lancar yang tersedia. 
Tabel Perhitungan Current Rasio

Tahun 2014 s/d 2016

\begin{tabular}{|c|c|c|c|}
\hline Tahun & Aktiva Lancar & Hutang Lancar & Current Rasio \\
\hline $\mathbf{2 0 1 4}$ & 13.342 .211 .641 & 293.940 .217 & $45,390 \%$ \\
\hline $\mathbf{2 0 1 5}$ & 14.071 .755 .266 & 149.661 .314 & $94,055 \%$ \\
\hline $\mathbf{2 0 1 6}$ & 15.990 .493 .516 & 331.561 .684 & $48,227 \%$ \\
\hline
\end{tabular}

Sumber data: Hasil olahan

Dari perhitungan diatas bisa kita lihat bahwa besarnya rasio lancar selama 4 tahun terakhir diatas mengalami fluktuasi, dimana pada tahun 2014 diperoleh rasio lancar sebesar 45,390\% dan mengalami kenaikan pada tahun 2015 sebesar $48,665 \%$ sehingga besarnya rasio lancar menjadi 94,055\%. Pada tahun 2016 rasio lancar perusahaan mengalami penurunan dari tahun

sebelumnya sebesar 45,828 sehingga menjadi $48,227 \%$.

b. Rasio Cepat (Quick Ratio atau Acid Test Ratio)

Rasio cepat merupakan rasio yang menunjukkan kemampuan perusahaan dalam membayar kewajiban atau utang lancar dengan aktiva lancar tanpa memperhitungkan nilai persediaan.

Tabel Perhitungan Quick Rasio

Tahun 2014 s/d 2016

\begin{tabular}{|c|c|c|c|}
\hline Tahun & Aktiva lancar-Persedian & Hutang Lancar & Quick Rasio \\
\hline $\mathbf{2 0 1 4}$ & 13.339 .351 .216 & 293.940 .217 & $13,34 \%$ \\
\hline $\mathbf{2 0 1 5}$ & 14.068 .894 .841 & 149.661 .314 & $14,07 \%$ \\
\hline $\mathbf{2 0 1 6}$ & 15.987 .633 .091 & 331.561 .684 & $15,99 \%$ \\
\hline
\end{tabular}

Sumber data: Hasil olahan

Pada tahun 2014 perusahan memperoleh quick rasio sebesar 13,34\% dan di tahun 2015 perusahahn mengalami peningkatan sebesar $0,73 \%$ sehingga quick rasio yang di peroleh perusahaan pada tahun 2015 sebesar 14,07\%. Pada tahun 2016 perusahaan mengalami penaikan kembali sebesar $15,99 \%$ daru perhitungan quick rasio di atas perusahaan mampu memaksimalkan persediaan yang tersedia pada perusahaan
2. Rasio Solvabilitas

Menurut Fred Weston dikutip dari Kasmir (150:2008), Rasio Solvabilitas adalah rasio yang digunakan untuk mengukur sejauh mana aktiva perusahaan dibiayai dengan utang dan mengukur kemampuan perusahaan untuk membayar seluruh kewajibannya, baik jangka pendek maupun jangka panajang apabila perusahaan dilikuidasi (dibubarkan). 
a. Rasio Hutang Terhadap Aktiva (Total Debt to Asset Ratio)

Rasio ini seberapa besar aktiva perusahaan dibiayai oleh utang atau seberapa besar hutang perusahaan berpengaruh terhadap pengelolaan aktiva. Rumusnya dibawah ini.

Tabel Perhitungan Debt Rasio

Tahun 2014 s/d 2016

\begin{tabular}{|c|c|c|c|}
\hline Tahun & Total Aktiva & Total Hutang & Debt Rasio \\
\hline $\mathbf{2 0 1 4}$ & 14.657 .224 .764 & 560.551 .013 & $3,82 \%$ \\
\hline $\mathbf{2 0 1 5}$ & 15.475 .878 .645 & 281.421 .320 & $1,81 \%$ \\
\hline $\mathbf{2 0 1 6}$ & 16.676 .381 .297 & 486.525 .186 & $2,91 \%$ \\
\hline
\end{tabular}

Sumber data: Hasil olahan

Dari tabel tersebut terlihat bahwa rasio hutang Pada Tahun 2014 dan 2015 miliki yang menurun sebesar 2,01\%. Pada Tahun 2016 mengalami peningkatan dari tahun sebelumnya sebesar $1,10 \%$ sehingga debt rasio PT. Pegadaaian Ulak Karang tergolong kurang sehat. Hal ini berarti bagi perusahaan tidak mampu membiayai hutang dari ktiva sehingga perusahaan susah untuk memperoleh dana pinjaman untuk meningkatkan modal sendiri.

3. Rasio Profitabilitas
Menurut Sofyan Safri Harahap (2008:304), "Rasio profitabilitas adalah kemampuan perusahaan mendapatkan laba melalui semua kemampuan, dan sumber yang ada seperti kegiatan penjualan, kas, modal, jumlah karyawan, jumlah cabang dan sebagainya".

\section{a. Margin Laba Kotor (Gross Profit Margin)}

Margin laba kotor adalah ukuran persentase dari setiap hasil sisa penjulan sesudah perusahaan membayar harga pokok penjualan.

Tabel Perhitungan Gross Profit Margin

Tahun 2014 s/d 2016

\begin{tabular}{|l|l|l|l|}
\hline Tahun & \multicolumn{1}{|c|}{ Laba kotor } & Penjualan & \multicolumn{1}{|c|}{ GPM } \\
\hline $\mathbf{2 0 1 4}$ & $2,636.198 .071$ & 2.636 .198 .071 & $2,63 \%$ \\
\hline $\mathbf{2 0 1 5}$ & 3.433 .643 .802 & 3.408 .166 .010 & $3,40 \%$ \\
\hline $\mathbf{2 0 1 6}$ & 4.443 .374 .910 & 1.054 .695 .130 & $3,43 \%$ \\
\hline
\end{tabular}

Sumber data: Hasil olahan 
Berdasarkan pada tabel diatas perusahaan mampu memperoleh gross profit margin pada tahun 2014 sebesar 2,63\% dan ditahun 2015 perusahaan mampu memperoleh laba sebesar 3,40\%. Pada tahun 2016 perusahaan kembali mampu meningkatkan kembali hasil laba yang diperoleh oleh perusahaan sebesar 3,43\%. Maka bisa disimpulkan bahwa perusahaan mampu memperoleh laba yang meningkat setiap tahunnya berarti kinerja perusahaan cukup efektif.

\section{b. Margin Laba Bersih (Net Profit Margin)}

Margin laba bersih adalah ukuran persentase dari setiap hasil sisa penjualan sesudah dikurangi semua biaya dan pengeluaran, termasuk bunga dan pajak.

\section{Tabel Perhitungan Net Profit Margin}

Tahun 2014 s/d 2016

\begin{tabular}{|l|c|c|c|}
\hline Tahun & Laba Bersih & Penjualan & NPM \\
\hline $\mathbf{2 0 1 4}$ & -1.087 .888 .002 & 2.636 .198 .071 & $41,26 \%$ \\
\hline $\mathbf{2 0 1 5}$ & -751.419 .641 & 3.408 .166 .010 & $22,04 \%$ \\
\hline $\mathbf{2 0 1 6}$ & 220.424 .385 & 3.436 .365 .544 & $6,41 \%$ \\
\hline
\end{tabular}

Sumber data: Hasil olahan

Berdasarkan tabel diatas dapat dilihat laba bersih perusahaan mengalami kondisi yang stabil. Pada tahun 2014 laba bersih perusahaan sebesar $41,26 \%$ dan pada tahun 2015 sebesar 22,04\%. Pada tahun 2016 laba bersih perusahaan mengalami penurunan dari tahun sebelumnya sebesar $6,41 \%$, Semakin besar rasio yang diperoleh maka semakin baik, karena perusahaan mampu menciptakan laba yang cukup tinggi dari aktifitas penjualan,

\section{c. Return On Invesment (Rasio} Pengembalian Atas Aktiva)

Rasio ini mengukur pengembalian atas total aktiva setelah bunga dan pajak. Hasil pengembalian total atau total investasi menunjukan kinerja management dalam menggunakan aktiva perusahaan perusahaan untuk menghasilkan laba 
Tabel Perhitungan Return On Invesment

Tahun 2014 s/d 2016

\begin{tabular}{|l|c|c|c|}
\hline Tahun & Laba Bersih & Total Aktiva & ROI \\
\hline $\mathbf{2 0 1 4}$ & -1.087 .888 .002 & $14,657,224,764$ & $7,42 \%$ \\
\hline $\mathbf{2 0 1 5}$ & -751.419 .641 & $15,475,878,645$ & $4,58 \%$ \\
\hline $\mathbf{2 0 1 6}$ & 220.424 .385 & $16,676,381,297$ & $1,32 \%$ \\
\hline
\end{tabular}

Sumber data: hasil olahan

Dari tabel diatas dapat dilihat ROI PT. Pegadaian Ulak Karang mengalami kondisi yang naik turun. Pada Tahun 2014 ROI perusahaan sebesar $7,42 \%$. Pada tahun 2015 perusahaan mengalami penurunan sebesar 2,84\% sehingga ROI perusahaan menjadi $4,58 \%$. Pada Tahun 2016 perusahaan mengalami penurunan kembali sebesar 3,36\% sehingga ROI menjadi $1,32 \%$. Perusahaan masih tergolong kurang baik dalam kinerja keuangan.

\section{Kesimpulan dan Saran \\ Kesimpulan}

Berdasarkan analisis kinerja keuangan dengan menggunakan rasio likuiditas, solvabilitas, dan profitabilitas dalam menilai kinerja keuangan pada PT. Pegadaian Ulak Karang padang dari tahun 2014 sampai dengan tahun 2016, dapat ditarik kesimpulan sebagai berikut:

\section{Tingkat Likuiditas PT.} Pegadaian Ulak Karang pada tahun 2014 sampai dengan 2016 kurang efesien atau kurang baik. Berdasarkan penilian current rasio dan quick rasio, tingkat likuiditas PT. Pegadaian Ulak Karang menunjukan bahwa perusahaan kurang bisa mengelola hutang jangka pendeknya. Dari segicurrent rasio menunjukan bahwa perusahaan kurang mampu mengelolah hutang lancarnya sehingga setiap tahunnya perusahaan mengalami perubahan yang jauh dari tahun sebelumnya. Jika dilihat dari quick rasio menunjukan perusahaan cukup efektif dengan kinerja keuangannya.

2. Tingkat Solvabilitas PT. Pegadaian Ulak Karang dari tahun 2014 sampai dengan tahun 2016 sangat baik, karena terlihat setiap tahunnya menglami penurunan dan peningkatan yang tidak terlalu jauh, hal ini menunjukan bahwa aktiva yang dimiliki perusahaan sangat tergantung pada hutang yang ada padaperusahaan.

3. Tingkat Profitabilitas PT. Pegadaian Ulak Karang dari tahun 2014 sampai tahun 2016 secara keseluruhan juga menunjukan rasio yang berfluktuasi atau tidak menentu dari tahun ketahunnya. Kenaikan atau penurunan ini terjadi karena menurunnya jumlah laba bersih dan meningkatnya jumlah aktiva. Tetapi kalau dilihat dari tingkat rasio profitabilitas secara keseluruhan sudah tergolong baik. 
Jika dilihat hasil keseluruhan yang telah diteliti berdasarkan rasio likuiditas, solvabilitas, prifitabilitas perusahaan cenderung berfluktuasi dan ketidakstabilan atas kinerja perusahaan. Meskipun demikian PT. Pegadaian Ulak Karang tetrmasuk kedalam kategori baik dan efektif.

\section{Saran}

Berdasarkan masalah yang yang dihadapi dalam perhitungan kinerja perusahaan, maka saran saran yang diberikan sebagai berikut:

1. Dari segi likuiditasnya, perusahaan mampu memenuhi hutang jangka pendeknya. Hal ini di buktikan dengan efektifnya kinerja perusahaan sehingga mampu mengatur hutang lancarnya, perusahaan seharusnya menjaga dan meningkatkan kemampuan dalam mengelola hutang yang segera dapat dipenuhi.

2. Dari segi solvabilitasnya, perusahaan juga menunjukan kemampunannya dalam menangani hutang-hutangnya untuk mempertahankan agar perusahaan tidak likuid. Dari debt rasio yang di tunjukan perusahaan mampu mengelola hutangnya dengan sangat baik dan efektif. Meskipun demikian perusahaan harus menjaga kinerja keuangan perusahaan agar tidak terjadi penurunan pada tahun - tahun selanjutnya yang bisa juga mengakibatkan perusahaan tidak likuid.

3. Dari segi
$\begin{aligned} & \text { perusahaan } \\ & \text { meningkatkan }\end{aligned}$ lebih $\begin{array}{r}\text { profitabilitas, } \\ \text { kinerja }\end{array}$ keuangannya dalam menghasilkan laba atau pendapatan bagi perusahaan yang akan dapat menunjang kegiatan operasional perusahaan. Perusahaan bisa mengelola laba yang dihasilkan menjadi asset yang menghasilkan, yaitu dengan mengelolanya dalam bentuk kredit dan membeli surat-surat berharga yang mana bisa membantu perusahaan ketika kesulitan dalam likuiditasnya.

4. Dari pihak manajemen perusahaan, harus bisa mempertahankan kinerja perusahaan dalam mengelola keuangannya, agar perusahaan tidak masuk dalam kategori yang tidak sehat

\section{DAFTAR PUSTAKA}

Harahap Sofyan Syafri, (2008). Analisis Kritis atas LaporanKeuangan, PT.Raja Grafindo Persada, Jakarta.

Kasmir, (2012). Analisis Laporan Keuangan, Edisi ke 1-5, Rajawali Pers, Jakarta.

Munawir, (2004). Analisa Laporan Keuangan, Liberty, Yogyakarta.

Munawir, 2000. Analisa Laporan Keuangan, Liberty, Yogyakarta

Riyanto, Bambang, (2001), Dasar-dasar Pembelajaran Perusahaan, Edisi Keempat, Cetakan Ketiga, BPFE UGM, Yogyakarta.

Sartono Agus, (2005), Manajemen keuangan, BPFE, Yogyakarta.

Soernarno, (2004), Pengantar Akuntansi, Edisi Kelima, Cetakan pertama, Saalemba Empat, Jakarta. 
Sugiono Arief, dan Edy Untung, (2008). Analisis Kritis Atas Laporan Keuangan, Jakarta, PT.Raja Grafindo.

Syamsuddin, Lukman, (2000), Manajemen Keuangan Perusahaan, (Konsep Aplikasi Dalam Perencanaan Pengawasan dan Pengambilan Keputusan), PT. Raja Grafindo, Jakarta. 